\title{
Environmental Impact Assessment Using Mathematical Matrixes Case: Qaen Steel, South Khorasan, Iran
}

\author{
Javad Dawoudian", Seyed Saeedreza Ahmadizadeh \\ Department of Environmental Science, University of Birjand, Birjand, Iran \\ Email address: \\ Jav_1367@yahoo.com (J. Dawoudian), sahmadi@birjand.ac.ir(S. S. Ahmadizadeh) \\ ${ }^{*}$ Corresponding author
}

\section{To cite this article:}

Javad Dawoudian, Seyed Saeedreza Ahmadizadeh. Environmental Impact Assessment Using Mathematical Matrixes Case: Qaen Steel, South Khorasan, Iran. International Journal of Environmental Monitoring and Analysis. Vol. 9, No. 5, 2021, pp. 122-128.

doi: $10.11648 /$ j.ijema.20210905.13

Received: July 20, 2021; Accepted: August 5, 2021; Published: September 3, 2021

\begin{abstract}
Qaen Steel Complex in South Khorasan, is located near the city Nimbolook. The aim of this study is assessment of project effects on environment by mathematical matrices. Significantly impact the results are classified in 4 groups: L: Low - M: Medium - H: High - VH: Very High. The results show that the low-and medium-classes were affected on the environment and high and very high classes have a little effect on the environment so any project works are not in very high class. On the other hand, the results show that for the most part, by the interaction of factors relating to the middle class and the poor, the most interactions for basic factors were for medium and low class. The most interaction effects for complimentary factors were for the low class. To reduce and control the negative effects of those projects were proposed. Using conventional environment improvement, erosion control, proper site selection and facility services to the environment, green space development, soil stabilization, alignment properly access roads, fields, forest and pasture restoration of organizing activities, site selection and proper villas Integration Projects with the least damage to the environment and create green space, restaurants and vegetation at specified times.
\end{abstract}

Keywords: Environmental Impact Assessment, Steel, Mathematical Matrices

\section{Introduction}

Human is the most important and effective factoring in environmental change. Considering that development and environment are two integral issues, it is necessary that by accessing and using environmental management tools, enter in all development programs at least to the resources and environment. Not paying attention the short-term effects and long-term of different projects will arise the main problems for humans [8]. It should however, be noted that the long and short-term effects of the different projects will pose serious problems to the population [7]. The development of urbanization, the gradual transformation of rural areas and agricultural communities into urban and industrial areas has led to changes in human relations with the environment. These changes are due to the lack of environmental control and monitoring. The balance, coordination and ordering of the components of nature are the essential requirements of the environment. If this balance changes due to some conditions, it will be damaged to all the components and structure of living beings, and at the head of that human being [16]. Evaluating environmental impacts is a tool in the service of development strategies and projects that has been recommended and approved in many countries' programs by many regional groups and International agencies $[9,3]$. The use of common methods of environmental improvement such as erosion control, proper location of facilities, and the creation of green spaces is essential to mitigate the impact of projects on the environment [4]. With the emergence of harmful effects of human activities, various instruments and methods have been developed and used to create balance and compatibility between activities and the environment. One of these methods is the Environmental Impact Assessment (EIA), which identifies the environment and understands its importance, examines the effects of different parts or activities of a design on the environment, and finally, according to The results of this work provide solutions to create greater compatibility [19]. Human activities are bigger 
than nature can do self-healing, an appropriate solution to minimize its effects and correct it is to predict the environmental impacts before the activities are implemented [6]. Concept and Objectives of Environmental Impact Assessment: Environmental impact assessment is the systematic identification and evaluation of the impacts of projects, programs and plans on the physical, chemical, biological, cultural, and socio-economic components of the environment, in other words, it is a method for determining, predicting and interpreting environmental impacts, An activity on the components of the environment, public health and the health of ecosystems that human life depends on. Environmental assessments in different parts of the world is called EI, EIA [12]. the negative impacts of the industry are avoidable. The proceedings such as developing a proper drainage network to prevent leakage and infiltration into the soil and groundwater, using biofilters, regular ventilation and aeration to prevent the creation of anaerobic conditions and odor distribution and tree planting around the factories and alternative areas are reducing the negative effects of the projects [5].

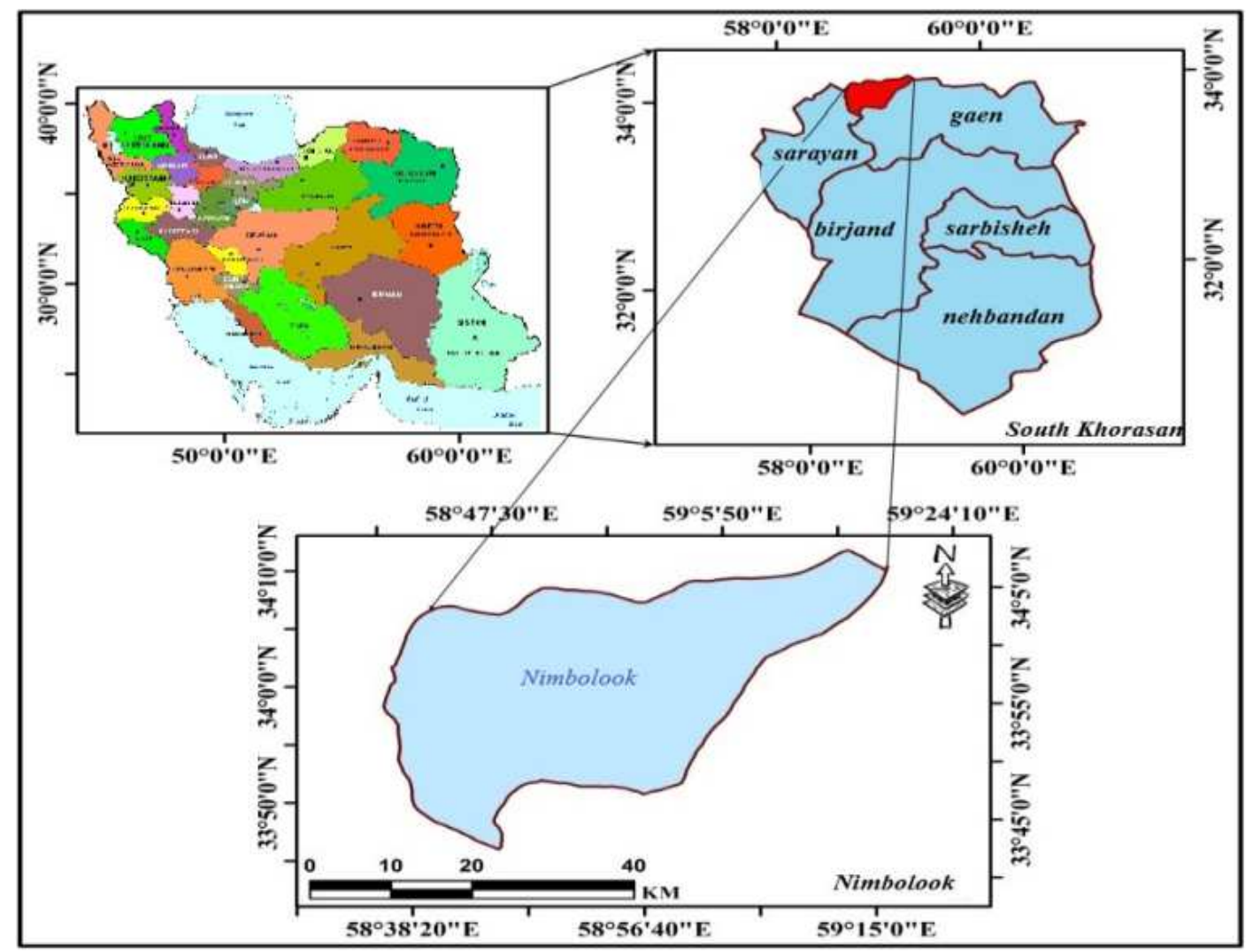

Figure 1. Schedule location.(Source: authors).

\section{The Necessity of Evaluating the Effects}

In the present situation, Iran is witnessing two major waves of internal and external changes in the field of the environment and its theoretical and practical issues. An international approach to solving environmental problems and the dynamics of political, social and economic developments within the borders has led to the expansion of studies that require that the response to them required looking for infrastructure solution and structured planning at the national and regional levels [13]. West man, W. E in 1985 proposed a cost-benefit analysis. This method consists of a variety of economic tools that value project components and gains from the project and determine the benefits and costs of the project. Pastakia [18]. first proposed a rapid impact assessment matrix in 1998, in which environmental components are divided into four groups. In (2007), Rudgarmi used a multi-criteria evaluation method for evaluating options that is implemented in the Geographic Information System and enables system to Checks out the combination of the effects and the status of options in each environment in a descriptive way and illustrates the desirability and lack of desirability of any development in the environment as a map. In (2011), Salehi [21]. and colleagues examined the application of fuzzy logic in assessing environmental impacts for Sangan iron ore. panahandeh and Abedinzadeh [17]. assessed the effects of the Yazd Composting Plant in 2007. For this study used the checklist of interactive effects questionnaire and Listometry check. In (2012), Salehi and colleagues [20]. reviewed the environmental impacts of the Birjand industrial town by using mathematical matrix and geographic information system. Mendez Paolini Adriana et al., In (2008), carried out a research study to determine the environmental impact indicators for seven of the landfills in the stadiola, in 
accordance with the terms and conditions of the assessment in Venezuela, and concluded that surface water, groundwater, air quality, Soil, and general health are key determinants in the assessment [11]. Salman Mahini et al. [22]. using the RIAM method to evaluate the re-effects of proposed landfill areas and the establishment of compost industries in Golestan province. In this study, the parameters were divided into four physical-chemical, biological-ecological, socio-cultural and economic-operational groups. In this research, the results obtained were different from the overall evaluation results. Sarabi and colleagues in (2011) using fuzzy mathematical matrix, evaluated the effects of development of proposed landfills in Golestan province and selected the best option for landfill. Mazlomi and Ahmadizadeh,[10] in 2008, carried out an assessment of the environmental impacts of the industrial city of Birjand using the Iranian matrix method and approved the values of between +5 and -5 projects with corrective options.

\section{Materials and Methods}

Ghaenat Steel Complex is located in South Khorasan Province, near the city of Semi-Block in geographical coordinates $\mathrm{X}=33,5530$ North and $\mathrm{Y}=590014$ East with a total area of 604 hectares. The license for the construction of this complex has been approved with the aim of producing 800,000 tons of light alloy steel ingot per year. (Figure 1).

\subsection{Mathematical Matrix Research Method}

The assessment of the effects of development will take several steps to ensure that all predictive effects are taken into account. The usual conditions follow the three stages [20] which include:

1. Description of the project and environmental characteristics.

2. Identification and prediction of the effect.

3. Valuation of the significance of the project's description of the project and the characteristics of the environment.

The first step is based on the interaction matrix. At this stage, experts and decision makers define the project activities and the environmental components that may be affected, and then experts and decision makers each separately evaluate the environmental components in the matrix cells. And then the criteria are defined as the two profiles of interactions and environmental susceptibility [2].

\subsection{Environmental Factors}

1) Air pollution and micro-climate. Identification and prediction of the effects of a steel plant on the region's climate is possible. Certain effects of certain activities, such as the use of vehicles, the construction of buildings and the increase of air outflows, can lead to climate changes, especially in the micro-clima of the factory site and around it [13].

2) Water Pollution: Physical actions such as river flow changes, causing ecological changes. Additionally, sedimentation and increase of sediment in the river, causes the flow of water to flow and reduces its depth. The drainage of water in the waters also affects the fish, with its cumulative affects significant [13].

3) Sound Pollution: The noise in the construction stages and possibly exploitation will be more than the current level. Linear noise sources can include traffic and vehicle traffic for entering and leaving the area and its perimeter. Therefore, local residents will be disturbed due to increased noise that results in noise pollution [13].

4) Biodiversity: The cutting of plants for purification or fuel consumption is another activity that is usually carried out in the construction phase. Reducing vegetation causes changes in human and animal populations and causes many of them to emigrate. Animal species are also lost due to the loss of their habitat or the inevitable emergence of new habitats and shelters that can find their ecological conditions.

5) Economic, social and cultural environment: Economic, social at constructional stages are exploited or are undergoing changes. Air pollution caused by project activity can affect the population of the region. The deployment of the project is likely to attract a large population. Ultimately, the decline or increase in population will affect the local economy. Cultural environments can cause serious damage to the project. Tourist and recreational centers, ancient monuments, historical, cultural and religious monuments are especially among the first places where the project activity produces harmful effects [14].

\subsection{Evaluation and Weighting of Mathematical Matrix Criteria}

After weighting and valuing for each of the main and complementary criteria by experts, the importance of mutual effects was assessed by a series basic index and supplementary index. The intensity of interaction between project activities and environmental components was evaluated using seven major criteria, magnitude and duration of effect, more effects, cumulative effects and differences of opinion, as well as the criterion of compensation effect.

\subsubsection{Calculation of Basic Criteria}

Basic criteria include magnitude, extension and duration of effect. First, the experts used the matrix base scores for each of the three options, and finally, applying the researcher's opinion and analyzing expert opinions, the final weight was applied to the matrices.

Basic criteria are essential for defining interactions. While the complementary criteria are the criteria that complete these descriptions, they can do not described in the description of the effects. Scoring is based on the scaling scale from 1 to 9 [1].

From these two profiles (base and complementary), the quantitative effect between the two variables $i$ and $j$ can be estimated. The variables $\mathrm{i}$ and $\mathrm{j}$ represent, respectively, the 
environmental components and the activities of the project.

Equation (1):

$$
E D_{i j}=1 / 27\left(M_{i j}+E_{i j}+D_{i j}\right)
$$

In these equations: the magnitude of the effects; the extent of the effects; the duration of the effects; the components of the environment; the activities of the project $[2,15]$.

\subsubsection{Calculation of Complementary Criteria}

Complementary criteria include the combined effects of synergy, cumulative effects and controversy that there is about the effects. Scores are considered for each of the complementary criteria in the range of 1 to 9 .

Equation (2):

$$
S A C_{i j}=1 / 27\left(S_{i j}+A_{i j}+C_{i j}\right)
$$

In these equations: $S_{i j}$ more effects; $A_{i j}$ cumulative effects; $C_{i j}$ disagreements; $i$ environmental components; $j$ project activities [2, 15].

\subsubsection{Calculation of Interactions Between Project Activity and Environmental Components $\left(I_{i j}\right)$}

After calculating the baseline and complementary criteria, the results were included in the studies of Bukhorkoes Tapia et al. In Equation (3-3) and their results were used to calculate the significant effects.

\subsubsection{Calculate Meaningful Effects}

In this stage, the results of complementary criteria, basal measures, interactions and compensatory effects were used to calculate meaningful effects according to the studies of Bukhorvoes Tapia et al. in the following equation.

Equation (3):
Equation (4):

$$
I_{i j}=M E D_{i j}^{\emptyset}
$$

$\mathrm{G}_{\mathrm{ij}}$ : Significance level, $\mathrm{T}_{\mathrm{ij}}$ : Compensation factor, $\mathrm{I}_{\mathrm{ij}}$ : Effective interaction between project activity and environmental components.

\subsubsection{Calculation of Compensation Profile}

This equation is used to obtain meaningful effects.

Equation (5):

$$
G_{i j}=I_{i j} \cdot\left[1-\left(\frac{T_{i j}}{9}\right)\right]
$$

Equation (6):

$$
\mathrm{F}_{\mathrm{ij}}=1-\mathrm{T}_{\mathrm{ij}} / 9
$$

Finally, we divide the effects into four groups: [2].

The Little effect $(0.0-0.24)$, Moderate effect $(0.25-0.49)$, Great effect (0.50-0.74), high effect (1- 0.75).

Based on the above division, the final conclusion is made.

\section{Results and Discussion}

The results of this research in this section are presented below after reviewing and applying the opinions of experts in project evaluation.

\subsection{Calculate Basic Index}

The results of calculating the basic index (magnitude, extent, and duration of effect) according to the experts'

\begin{tabular}{|c|c|c|c|c|c|}
\hline Parameters Activities & Excavator & Leveling & Building a way & Transportation & Waste and waste disposal \\
\hline Air pollution and microclimate & 0.70 & 0.33 & 0.48 & 0.44 & 0.29 \\
\hline water pollution & 0.14 & 0.03 & 0.14 & 0.07 & 0.74 \\
\hline Soil erosion & 0.66 & 0.37 & 0.33 & 0.22 & 0.44 \\
\hline Noise pollution & 0.33 & 0.37 & 0.48 & 0.48 & 0.03 \\
\hline Ground deformation & 0.70 & 0.29 & 0.55 & 0.18 & 0.44 \\
\hline Habitat destruction & 0.51 & 0.25 & 0.59 & 0.22 & 0.48 \\
\hline Public health threat & 0.14 & 0.14 & 0.11 & 0.22 & 0.62 \\
\hline
\end{tabular}
opinions for the project are presented in the following tables, respectively. These results are obtained using equation (1).

\begin{tabular}{|c|c|c|c|c|c|}
\hline $\begin{array}{ll}\text { Parameters } & \text { Activities } \\
\end{array}$ & Excavator & Leveling & Building a way & Transportation & Waste and waste disposal \\
\hline Air pollution and microclimate & 0.11 & 0.11 & 0.14 & 0.18 & 0.07 \\
\hline water pollution & 0.14 & 0.14 & 0.11 & 0.11 & 0.11 \\
\hline Soil erosion & 0.11 & 0.11 & 0.07 & 0.14 & 0.07 \\
\hline Noise pollution & 0.11 & 0.11 & 0.11 & 0.11 & 0.07 \\
\hline Ground deformation & 0.11 & 0.11 & 0.11 & 0.07 & 0.14 \\
\hline Habitat destruction & 0.40 & 0.07 & 0.25 & 0.07 & 0.07 \\
\hline Public health & 0.07 & 0.07 & 0.11 & 0.07 & 0.40 \\
\hline
\end{tabular}

$$
\emptyset=1-S A C_{i j}^{I}
$$

Table 1. Shows the results of calculating basic index (MED). (Source: authors).

Table 2. Results from Calculation of Basic index (SAC) (Source: authors). 


\subsection{Calculation of Complementary Criteria}

In order to calculate the complementary criteria, due to effects of synergy between the variables, the cumulative effects and controversy of the scores were taken according to the conditions of the region and compared to the project activities and environmental components, these results are obtained using equation (2) And is presented in the table 2.

\subsection{Calculation of the Effect of Project Activity on the Environmental Components $\left(I_{i j}\right)$}

To calculate the impact of project activities on the environmental components, first we obtain the value of $\varphi$ from equation (3) and apply the result in Equation (4). The results obtained for the project activity on the environmental components are presented in Table 3.

Table 3. Calculation of the effect of project activity on the environmental components $\left(I_{i j}\right)$. (Source: authors).

\begin{tabular}{|c|c|c|c|c|c|}
\hline $\begin{array}{ll}\text { Parameters I } & \text { Activities } \\
\end{array}$ & Excavator & Leveling & Building a way & Transportation & $\begin{array}{l}\text { Waste and } \\
\text { waste disposal }\end{array}$ \\
\hline Air pollution and microclimate & 0.73 & 0.37 & 0.53 & 0.51 & 0.32 \\
\hline water pollution & 0.19 & 0.06 & 0.18 & 0.09 & 0.76 \\
\hline Soil erosion & 0.69 & 0.41 & 0.36 & 0.27 & 0.47 \\
\hline Noise pollution & 0.37 & 0.41 & 0.52 & 0.52 & 0.04 \\
\hline Ground deformation & 0.73 & 0.33 & 0.59 & 0.20 & 0.50 \\
\hline Habitat destruction & 0.67 & 0.28 & 0.67 & 0.24 & 0.50 \\
\hline Public health & 0.17 & 0.17 & 0.14 & 0.24 & 0.76 \\
\hline
\end{tabular}

The Effect of effect Compensating factor on the Mathematical Matrix In the Mathematical Matrix, the effect Compensating factor $\left(T_{\mathrm{ij}}\right)$ is used to reduce or eliminate negative effects and increase positive effects. This factor represents the compensatory activity that is being undertaken in the industry to reduce the effects of project activity. $T_{\mathrm{ij}}$, Considering the destructive effects and the consideration of the conditions of each region, they were rated in the interval from 1 to 9 [20]. The result of this scoring was laid out in the formula of calculating meaningful effects (Equivalent 5).

\subsection{Calculate Meaningful Effects}

The results of calculating the effect of project activity on environmental components $\left(I_{i j}\right)$ as well as the effect factor compensation were used to achieve significant effects. The meaningful calculation of the effects was carried out using Equation (5) and the results are presented in Table 4.

Table 4. Results from calculating the effect of project activity on environmental components $\left(I_{i j}\right)$. (Source: authors).

\begin{tabular}{llllll}
\hline Parameters & Activities & Excavator & Leveling & Building a way & Transportation \\
Air pollution and microclimate & 0.33 & 0.33 & 0.77 & 0.77 & 0.44 \\
disposal
\end{tabular}

Table 5. Results from the compensation index (fij). (Source: authors).

\begin{tabular}{|c|c|c|c|c|c|}
\hline $\begin{array}{ll}\text { Parameters } & \text { Activities } \\
\end{array}$ & Excavator & Leveling & Building a way & Transportation & $\begin{array}{l}\text { Waste and waste } \\
\text { disposal }\end{array}$ \\
\hline Air pollution and microclimate & 0.24 & 0.12 & 0.41 & 0.22 & 0.10 \\
\hline water pollution & 0.15 & 0.04 & 0.14 & 0.08 & 0.34 \\
\hline Soil erosion & 0.30 & 0.27 & 0.24 & 0.24 & 0.41 \\
\hline Noise pollution & 0.25 & 0.27 & 0.46 & 0.46 & 0.04 \\
\hline Ground deformation & 0.56 & 0.26 & 0.46 & 0.18 & 0.22 \\
\hline Reduce biodiversity & 0.13 & 0.13 & 0.34 & 0.30 & 0.33 \\
\hline Public health & 0.09 & 0.09 & 0.11 & 0.19 & 0.25 \\
\hline
\end{tabular}

\subsection{Division of Significant of Effects}

Results of meaningful effects in 4 categories: L: Low; M: Medium; H: High; VH: Very high.

The results of this categorization are presented in Table
6 and 7. To illustrate the importance of the factor of the significant division of the effects, the effects are shown in two tables, in Table 6, the partition is without compensation factor, and Table 7 is corrected by applying the factor. 
Table 6. The results of the meaningful calculation of the effects $\left(G_{i j}\right)$. (Source: authors).

\begin{tabular}{lllllll}
\hline $\begin{array}{l}\text { Total } \\
\text { effects }\end{array}$ & $\begin{array}{l}\text { Disposal of waste } \\
\text { and waste }\end{array}$ & $\begin{array}{l}\text { Transportation of } \\
\text { materials }\end{array}$ & $\begin{array}{l}\text { Construction of the main } \\
\text { and secondary routes }\end{array}$ & $\begin{array}{l}\text { Leveling and } \\
\text { squaring }\end{array}$ & $\begin{array}{l}\text { Embankment } \\
\text { and excavator }\end{array}$ & Division of effects \\
\hline 12 & 1 & 4 & 2 & 3 & 2 & $0-0.24$ \\
1 \\
12
\end{tabular}

Table 7. The results of the classification without the effect of the compensation factor. (Source: authors).

\begin{tabular}{|c|c|c|c|c|c|c|c|}
\hline $\begin{array}{l}\text { Total } \\
\text { effects }\end{array}$ & $\begin{array}{l}\text { Disposal of waste } \\
\text { and waste }\end{array}$ & $\begin{array}{l}\text { Transportation } \\
\text { of materials } \\
\end{array}$ & $\begin{array}{l}\text { Construction of the main } \\
\text { and secondary routes }\end{array}$ & $\begin{array}{l}\text { Leveling and } \\
\text { squaring }\end{array}$ & $\begin{array}{l}\text { Embankment } \\
\text { and excavator }\end{array}$ & \multicolumn{2}{|c|}{ Division of effects } \\
\hline 23 & 4 & 6 & 3 & 5 & 5 & $0-0.24$ & $\mathrm{~L}$ \\
\hline 16 & 4 & 2 & 5 & 3 & 2 & $0.25-0.49$ & M \\
\hline 1 & 0 & 0 & 0 & 0 & 1 & $0.50-0.74$ & $\mathrm{H}$ \\
\hline 0 & 0 & 0 & 0 & 0 & 0 & $0.75-1$ & $\mathrm{VH}$ \\
\hline
\end{tabular}

\section{Conclusion}

The study of thematic records of industrial projects in Iran shows that in the past planning, the importance and values of natural resources and the environment have not been considered and have been designed and exploited without considering environmental considerations. The result of such measures has been the occurrence of various pollutions and severe destruction and depletion of environmental resources.

Environmental assessment can be considered as a mechanism that has been shown to be effective in providing short and long-term planning for both short and long term planning, through the provision of appropriate and logical ways of using human resources and natural resources. Knowledge of the community as a whole increases as the environmental assessment relates to the planning process. Project timelines can also reduce costs in scheduled times. As a result, the pressure on government finances decreases. On the other hand, environmental assessment, due to accelerated planning, will protect more resources and prevent irreparable effects on the environment and natural resources.

The results show that if the compensation profile is not applied, the sum of the effects in the first three classes is almost equal, that's mean without compensation index, low, medium, and large effects are equal to each other. This table is intended only to illustrate the role of the compensation profile. The compensation sheet specifies how much the effects can be adjusted and reduced. Activities that reduce the effects of the work can be done using a filter to reduce air pollution.

General diagram of the classification without affecting the compensation factor:

On the other hand, with the effect of the recurrence and reconsideration factor, we find that many of the negative effects are reduced, Table 8 shows that the effects are low and moderate, and many and very large classes make a small contribution, so that a very high class It is zero and does not include any of the project's activities in this category. Model number 2 shows this difference. General diagram of classification with effect compensation factor:

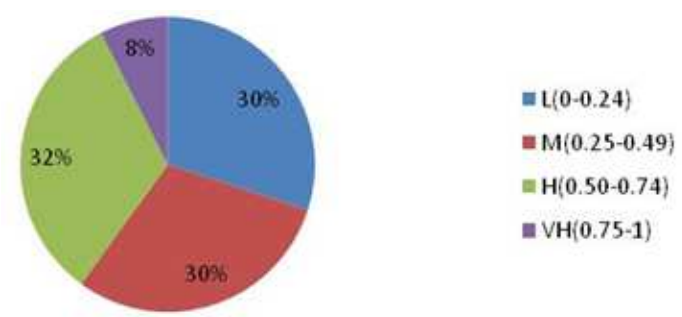

Figure 2. Project Impacts on the Environment, without Compensation. (Source: authors).

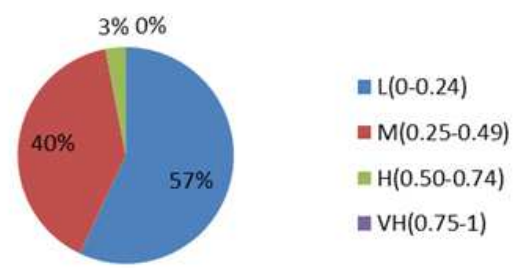

Figure 3. Project Effects on the Environment with Compensation Agent.(Source: authors).

Table 8. The results of classification with the effect of the compensation factor. (Source: authors).

\begin{tabular}{|c|c|c|c|c|}
\hline Factor & $\begin{array}{l}\text { Low } \\
\text { Effects (L) }\end{array}$ & $\begin{array}{l}\text { Medium } \\
\text { Effects (M) }\end{array}$ & $\begin{array}{l}\text { High } \\
\text { Effects (H) }\end{array}$ & $\begin{array}{l}\text { Very High } \\
\text { Effects (VH) }\end{array}$ \\
\hline (Basic) & 13 & 17 & 10 & 0 \\
\hline (Supplementary) & 36 & 3 & 1 & 0 \\
\hline (Impact) & 12 & 12 & 13 & 3 \\
\hline (Significance) & 22 & 17 & 1 & 0 \\
\hline
\end{tabular}

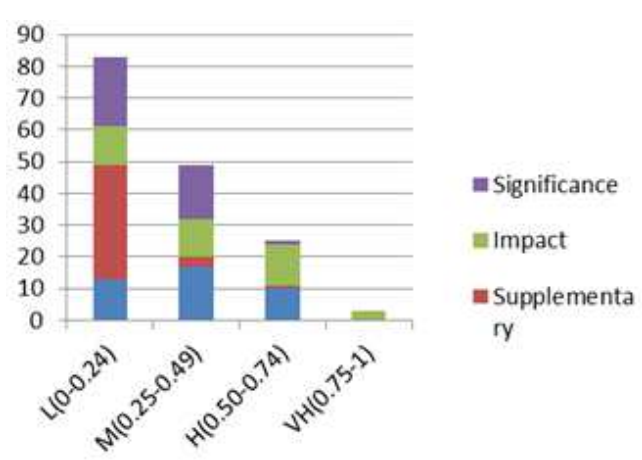

Figure 4. Overall assessment of environmental impacts using mathematical matrix. (Source: authors). 
On the other hand, the results show that for the basic factors, the most interactions are related to the middle and low classes and for complementary factors, the most interaction effects are low effects (Table 8 and Figure 4).

Assessing the effects of the Ghaen Steel Project shows that this industry has no negative impact on the region's environment. In order to reduce the possible negative impacts, it is suggested the corrective actions take place and to assess with more accuracy fuzzy methods are applied.

\section{References}

[1] Banai-Kashani, R., 1989, A New Method for Site Suitability Analysis: Analytical Hierarchy.

[2] Bojo'rquez-Tapia, L. A., Ezcurra, E., Garci'a, O, 1998. Appraisal of environmental impacts and mitigation measures through mathematical matrices. Environmental Management. 53: 91-99.

[3] Danida, 1994, Environmental assessment for sustainable development. Danish International Development Agency: Denmark.

[4] Dawoudian, J., Bahamin, S. \& Tantoh, H. B. 2021, Environmental impact assessment of cement industries using mathematical matrix method: case of Ghayen cement, South Khorasan, Iran. Environ Sci Pollut Res. https://doi.org/10.1007/s11356-020-12012-3

[5] Dawoudian, j., ahmadizadeh, sr. 2020 The fuzzification of mathematical matrix in the environmental impact assessment of steel industry, Ghayen, Iran. Computational Ecology and Software, 2020, 10 (4): 186-199.

[6] Duarte, O. G., Requena, I., Rosario, Y. 2007. Fuzzy Techniques for Environmental Impact Assessment in the Mineral Deposit of Punta Gorda (Moa, Cuba). Environmental Technology, 28, 659-669.

[7] Makhdoom, M. 1995, Foundation for the Study of Land, Tehran University Press.

[8] Makhdoom, M. 2003, Evaluation of Developmental Impacts on the Environment, Master's Degree, Faculty of Environmental Sciences, University of Tehran.

[9] McInnes RJ (2018) Sustainable development goals. In: The Wetland Book: I: Structure and Function, Management, and Methods.
[10] Mazlomi, S., Ahmadizadeh, S. S. 2008. Environmental Impact Assessment of Birjand Industrial Town, Proceedings of the 2nd Conference and Exhibition of Environmental Engineering.

[11] Me 'ndez, A. P; Ridao, A. R; Toro, M. Z; 2008. Environmental diagnosis and planning action for municipal waste landfill in Estado Lara (Venezuele). Renewable and Sustainable Energy Reviews 12: 752-771.

[12] Mirabzade, P., 1998. Guidance of Environmental impact assessment and development. 3rd edition. Conservation of Environment., Tehran. pp: 50-60.

[13] Monavari M., 2002. Environmental Impact Assessment Guide for Steel Industries, Kowsar Publications, Cultural-Traveling Center, First Edition.

[14] Monavari, M., 2005. Environmental Impact Assessment, Tehran, Mitra Publication, First Edition.

[15] Mussa M. 2018. Environmental Impacts of Hydropower and Alternative Mitigation Measures. Curr Investig Agric Curr Res 2:. doi: 10.32474/ciacr.2018.02.000133.

[16] Noori, J., Neshat, SH., 1995 Guidance of Environment and Development, first edition. Conservation of Environment., Tehran. pp: 100-120.

[17] Panahandeh, M., Abedinzadeh, N. 2007. Environmental Impact Assessment of Yazd Composting Plant, 10th National Conference on Environmental Health, Hamadan, 11 p.

[18] Pastakia C. M. R., Jensen, A., 1998. The Rapid Impact Assessment Matrix (RIAM) For EIA. Environmental Impact Assessment Review 18: 461-482.

[19] Rudgarmi, P. 2007. Evaluation of Developmental Options in Environmental Impact Assessment Using Purposeful Multivariate Evaluation, Journal of Environmental Science and Technology, Vol. 9, No. 4: 74-84.

[20] Salehi, A., Ahmadizadeh, S. R., Moradi, H., Salman Mahini, A., 2012. Environmental Impact Assessment of Birjand Industrial Town with Mathematical Matrix, Master's Thesis, Birjand University.

[21] Salehi, J., Ahmadi Zadeh, S. R., Moradi, H., Zahiri, H., 2011, Application of Fuzzy Logic in Environmental Impact Assessment (Case Study: Sangan Iron Ore Mining), Master's Thesis, Birjand University.

[22] Salman Mahini, A., Momeni, A; 2008. Income on Improving Environmental Impact Assessment Methods in Iran, National Conference on Development Impact Assessment. 